\title{
30th International Congress of Clinical Neurophysiology
}

We are happy to announce the 30th International Congress of Clinical Neurophysiology (ICCN2014) of the International Federation of Clinical Neurophysiology (IFCN).

The ICCN2014 will take place in Berlin from March 20-23, 2014 and will be organized in conjunction with the Annual Meeting of the German Society for Clinical Neurophysiology and Functional Imaging (DGKN) scheduled from March 19 -22, 2014.

Modern Clinical Neurophysiology is changing. The ICCN2014 will cover classical methods such as EMG, NCS, EEG, and evoked potentials in scientific sessions and educational courses, as well as advanced clinical neurophysiology using eventrelated brain potentials and fMRI, and modern therapeutic or interventional approaches such as invasive and noninvasive brain stimulation. It will also cover closely-linked imaging methods such as ultrasound, especially high-resolution ultrasound and MRI of muscle, nerve, and brain. ICCN2014 shall also show how these methods are embedded in the clinical context studying neuromuscular disorders, epilepsy, sleep, pain, cognitive and central movement disorders, brain plasticity in stroke, neurodegeneration and neuroinflammation, and others.

For more information, contact

Sebastian Leipelt

Online marketing

Conventus Congressmanagement \& Marketing GmbH

Carl-Pulfrich-Str.1 07745 Jena

fon 004936413116142

fax 004936413116243

sebastian.leipelt@conventus.de・www.conventus.de 